\title{
El español en los congresos internacionales.
}

\author{
Néstor de la Portilla Geada \\ Profesor de Psiquiatría. Universidad de Carabobo. Valencia. Venezuela \\ nestordelaportillageada@gmail.com
}

Con cierto asombro y algo de indignación leo el anuncio del próximo Congreso Europeo de Psiquiatría que se realizara el 2013 en Niza y en el que queda bien claro que el único idioma oficial es el inglés.

Se estima que en Europa hay aproximadamente 77.000 psiquiatras y en los países angloparlantes (Inglaterra e Irlanda) hay aproximadamente unos 7.000. Que 9 de cada 10 asistentes tengan que escuchar las ponencias, y lo que es más arduo, discutirlas en el idioma del décimo, no deja de ser grotesco.

Conozco las razones de los que defienden el inglés como lengua franca de las ciencias, pero aún así no creo justifiquen que el $90 \%$ de los asistentes tengan que esforzarse por expresarse con claridad en el idioma del $10 \%$.

Solo el número de psiquiatras de los países que el Dr. Santiago Ramón y Cajal hace poco más de un siglo recomendaba aprender sus idiomas (Francia, Alemania e Italia), excede unas seis veces el de los países angloparlantes de Europa.

En ese sentido el último congreso mundial de psiquiatría de 2011 que se celebró en Buenos Aires podría servir de referencia con su idioma inglés oficial, pero con toda una sección en español y portugués, que fue muy concurrida por psiquiatras latino americanos y europeos, en el que un grupo de Profesores franceses y suizos (Jean Garrabé, P. Chenivesse, M. Reca, D. Wintrebert, N. Feldman, P. Belzeaux y D. Zullino) dieron sus conferencias en buen español.

La asimilación es lo contrario de la exclusión.

En una reconocida publicación médica alemana apareció una encuesta hecha el año 2003 en la cual solo el 20\% de los médicos alemanes reconocía tener un buen conocimiento del inglés hablado y escrito, ¿Será muy distinto en los demás países europeos? (1).

Al parecer en ambas orillas del Atlántico, en el mundo hispanoparlante, la situación no es muy distinta respecto al conocimiento del inglés (2-5).

Inevitablemente vienen a la memoria los versos de Rubén Darío en "El cisne".

¿Tantos millones hablaremos inglés?

¿Ya no hay nobles hidalgos ni bravos caballeros?

¿Callaremos ahora para llorar después?

Atentamente 
CARTAS AL EDITOR

(1) Hasse W.Fischer RJ. The medical profession against Anglicization in medicine. Results of a survey. Dtsch Med Wochenschr 2003; 128(24):1338-41.

(2) Moussaoui D. ¿Cómo organizar un congreso de psiquiatría?

Publicado por la Asociación Mundial de Psiquiatría, 1999.

(3) Elkis H. Residencia médica: competencias mínimas e psiquiatría moderna $\operatorname{Rev}$ Bras Psiquiatr 1999; 21(3):137-138.

(4) Ribes R. Los profesionales españoles y el inglés. Panacea. 2009; 10(30) :180.

(5) Pérez Moltó FJ.El idioma inglés en medicina. De la conveniencia a la necesidad. Educación Médica. 2001; 4(17):202-208. 